\title{
Additive Manufacturing of structural materials for nuclear application and rapid mesoscale mechanical testing
}

Peter Hosemann ${ }^{1}$, jason Duckering ${ }^{2}$, Andrew Dong ${ }^{2}$, jeff Bickel ${ }^{2}$, Stuart Maloy ${ }^{3}$, Thomas Lienert ${ }^{3}$, Calvin Lear $^{3}$, Tuhin Mukherjee ${ }^{4}$ and Tarasankar DebRoy ${ }^{4}$

${ }^{1}$ University of California, Berkeley, United States, ${ }^{2}$ UC Berkeley, United States, ${ }^{3}$ LANL, United States,

${ }^{4}$ Penn State University, United States

Additive manufacturing addresses all aspects of manufacturing. Aerospace, machining, mining, or even medical applications make use of metal based additive manufacturing. Naturally metal additive manufacturing is also used in nuclear applications. The efforts of deploying additive manufactured components in nuclear power applications have been increased and large testing campaigns of additive manufactured parts are exposed to neutron irradiation today through various DOE sponsored programs. The majority of the previous programs are concerned with materials for light water reactor applications and therefore the properties of austenitic stainless steels[1-3]. Only recently scientists utilized it to manufacture ferritic martensitic materials [4-6], compositional graded materials [7], or even high entropy alloys [8].

This work focuses on ferritic martensitic materials produced via metal additive manufacturing. Previous work studied the microstructural characterization of powder bed laser fusion additively manufactured T91 which revealed that the material is largely ferritic and subsequent heat treatment is needed in order to obtain the desired ferritic/martensitic microstructure. However, recent work shows that laser engineering net shaped (LENS) AM processes deliver close to ready to use microstructures similar to what a quenched and tempered Ferritic martensitic material would look like. Figure 1 shows the microstructural image collected on AM produced nuclear F/M material.

Of course, in order to assess the viability and performance of these materials mechanical testing must be performed. In fact it is essential to rapidly probe the materials performance as a function of location on the build part, build direction, etc.. In order to achieve this, we developed advanced small scale and mesoscale mechanical testing bringing insight into the strength and failure modes of the material. We developed accelerated mesoscale sample fabrication methods based on ultrafast laser pulsed machining [9-10]. The system developed is able to manufacture small samples on any component in 2D and 3D. 2D sample geometry is cut using the system as it can be seen in Figure 2 on thin sheets while figure $2 \mathrm{~b}$ shows the 3D geometry manufactured using this tool. This approach allows one to probe specific regions of interest such as interlayer strength and deformation. In-situ deformation is observable during the testing inside the SEM. This work will show the combined conventional microscopy with mesoscale and microscale mechanical testing during further in-situ microcopy. 

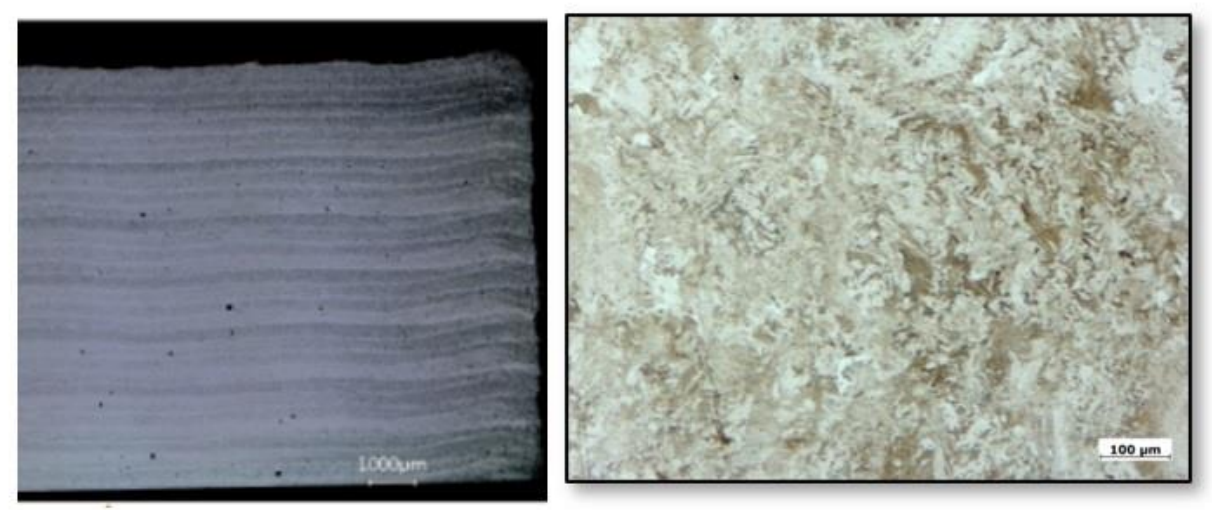

Figure 1. Optical microscopy of LENS produced T91.

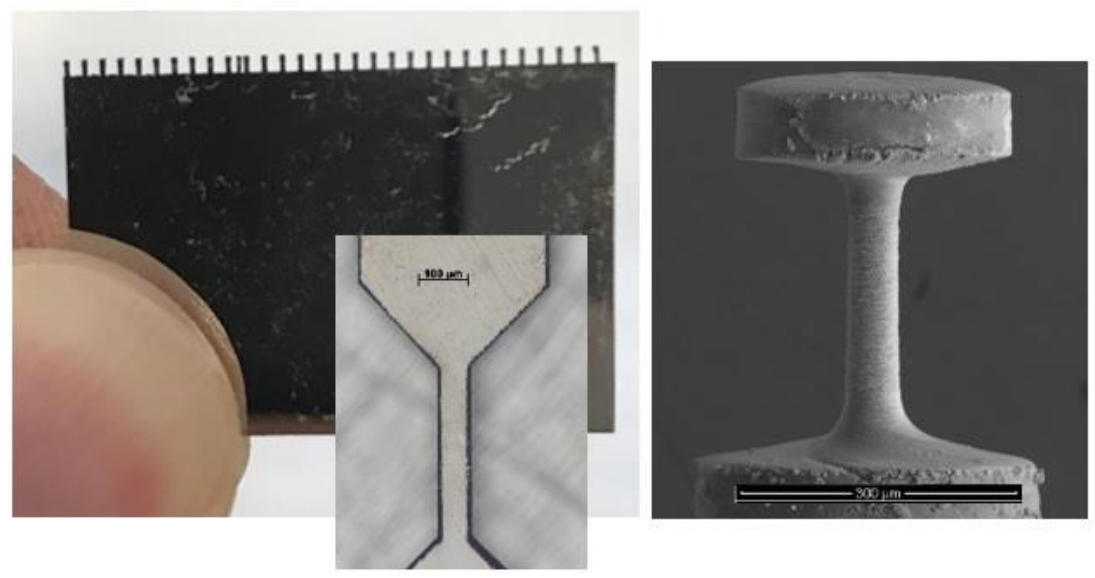

Figure 2. Femto second laser produced 2D a) and 3D b) tensile samples fabricated from steel.

References

[1] J. Simpson, J. Haley, C. Cramer, O. Shafer, A. Elliott, W. Peter, L,. Love R. Dehoff; ORNL/TM2019/1190

[2] Y. Zhong, L.-E. Rannar, L. Liu, A. Koptyug, S. Wikman, J. Olsen, D. Cui, Z. Shen, J. Nucl. Mat. 486 (2017) 234-245

[3] XiangyuSun, FeidaChen, HaiHuang, JiweiLin, XiaobinTang, Appl. Surf. Scie. (2019) 467-468

[4] G.Meric de Bellefon, K.M.Bertsch, M.R.Chancey, Y.Q.Wang, D.J.Thoma,J. NUcl.Mat. 523 (2019) 291-298

[5] N. Sridharan, M. N. Gussev, K.G.Field, J. Nucl.Mat. 521 (2019) 45-55

[6] B.P.Eftink, D. A. Vega, O. El Atwani, D. J. Sprouster, Y. Suk, J. Yoo, T. E. Steckley, Eda Aydogan, C. M.Cady, M. Al-Sheikhly, T. J.Lienert, S. A.Maloy

[7] A. Reichardt, A.A.Shapiro, R. Otis, R.P. Dillon, J.P. Borgonia, B.W. McEnerney,P. Hosemann, A.M.Beese, Int. Mat. Rev. 66 (2021) 1-29

[8] M. Moorehead, K. Bertsch, M. Niezgoda, C. Parkin, M. Elbakhshwan, K. Sridharan, C. Zhang, D. Thoma, A. Couet, Mat\&Design 187 (2020) 108354

[9] J. G. Gigax, Hi.Vo, Q. McCulloch, M. Chancey, Y.Wang, S. A. Maloy, N. Li, P. Hosemann, Scipta Mat 170 (2019) 145-149

[10] M.J.Pfeifenberger, M. Mangang, S. Wurster, J. Reiser, A. Hohenwarter, W. Pfleging D. Kiener, R. Pippan, Mat\& Design 121 (2017) 109-118 